\section{The Rhizometer - a device for measuring roots of tree seedlings}

\author{
by 1. K. Morrison and K. A. Armson
}

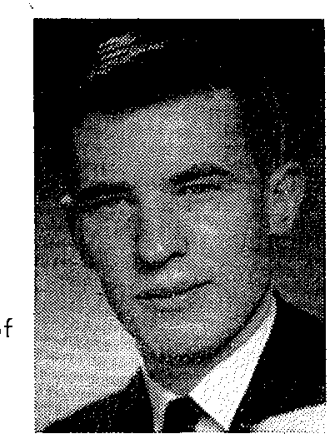

I. K. Morrison

C. K. Morrison

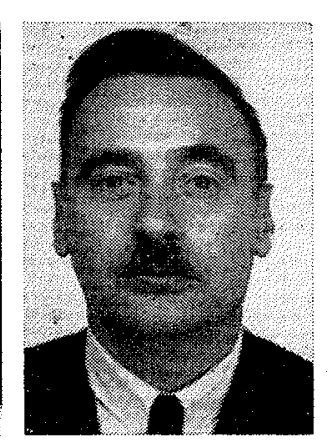

K. A. Armson

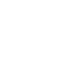

\begin{abstract}
A photoelectric device - the rhizometer which can be used to estimate root surface areas of seedlings is described. The advantage of this instrument is that it is rapid and non-destructive. The method gives comparable results to estimates obtained by direct measurement of diameters and lengths; in addition the estimates are highly reproducible. The technique used has considerable application in the assessment of root systems of seedlings grown under experimental conditions and also in the routine measurement of nursery production stock. Seedlings are capable of being planted out after root measurement by this technique.
\end{abstract}

In many studies of the responses of tree seedlings to various environmental factors, measurement of the root systems is of importance. The most often used measurement is that of root weight and it is common for shoot:root ratios (weight basis) to be used in comparisons of seedling development. For studies of nutrient absorption and also of the performance of seedlings when outplanted under different conditions, it is more logical to use a measure of root surface area, rather than that of weight. Recently Voigt, 1966, and Newman, 1964, have used and discussed the use of root area as a more useful parameter. Anyone who has endeavoured to determine root areas of even small seedlings by direct measurement is aware of the laborious nature of such an undertaking. A plea for studying the rooting volume of soil and for measurements of root surface area has been made by Wiersum (1961). Besides being laborious such measurements are also destructive - as is dry weight determination - and this is a further disadvantage.

Over a period of years, we have been concerned
Graduate Student and Assoc. Prof. of Forestry, Foculty of Forestry Toronto, Ontario. Oxf. 539 . 
series of holes drilled in the sides to allow warm air to escape. The upper unit 12 ins. by 12 ins. by 36 ins. high. The lower two inches of the upper unit has holes drilled in the plywood to act as vents for warm air. Immediately above this a frosted glass plate was installed. On this plate black cardboard or arborite sheets with openings of any convenient dimension (e.g. $10 \mathrm{~cm}$. by $20 \mathrm{~cm}$.) can be placed.

When measurements of root systems were made for seedlings which were to be replanted, a shallow tray made of acrylic plastic, the exact dimensions of the opening, was used and filled to the depth of one half inch with water. A sheet of plastic the same dimensions as the inside of the tray was then placed over the root to keep them in one plone. When calibrating the rhizometer all components e.g. tray, water and sheet of plastic must be in place.

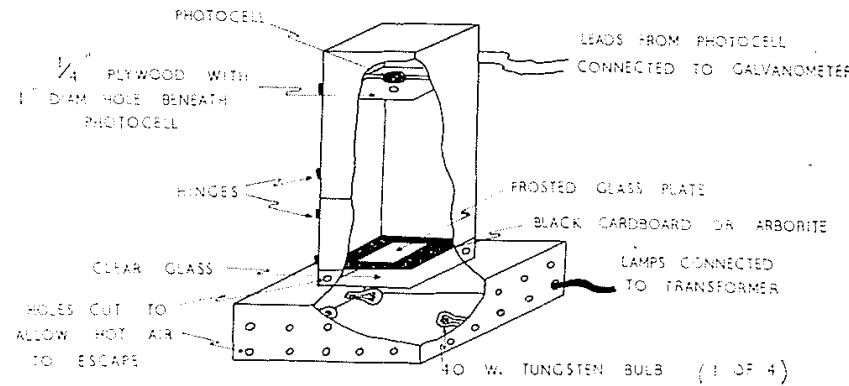

Figure 1. Diagram of rhizometer showing component parts.

\section{Calibration}

For any given size of opening, the galvanometer is adjusted to read 100 when no seedlings are placed on the plate. Thin pieces of arborite or black paper of known area are then placed in the opening and readings are taken from the galvanometer. An example of a calibration curve is shown in Figure 2. It will be noted that the calibration curve is a straight line.

\section{Measurement of Roots}

Roots to be measured are spread across the aperture and held in one plane by a glass plate. Alternatively the water filled plastic tray may be used if the seedlings are to be replanted. A reading is then taken from the galvanometer. This read-

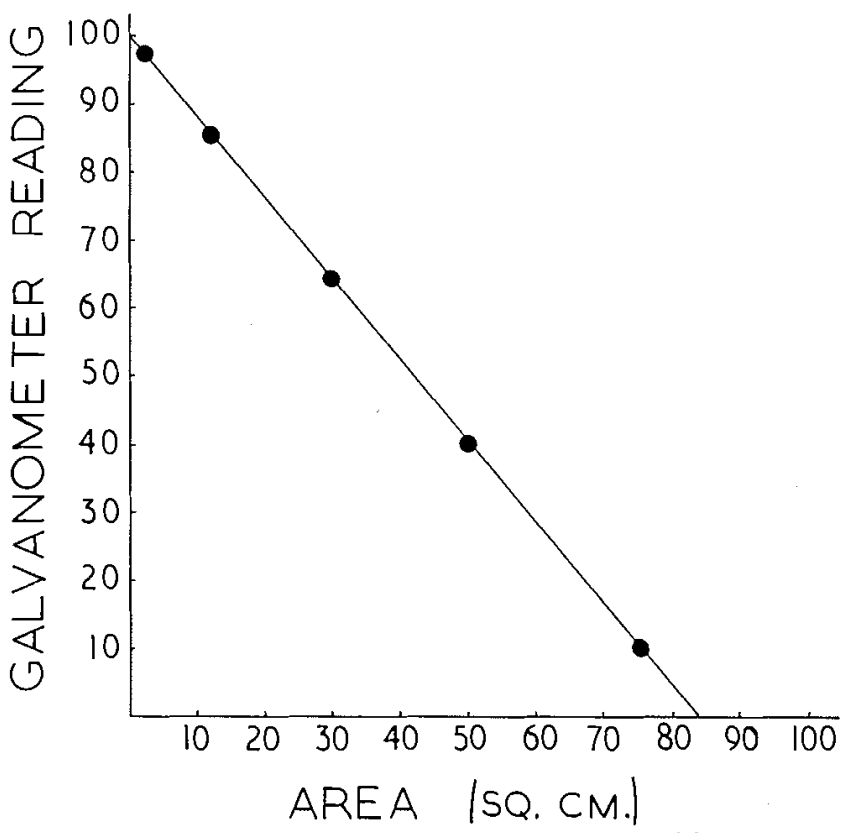

Figure 2. Calibration curve for an aperture of $200 \mathrm{sq} . \mathrm{cm}$. $(20 \times 10 \mathrm{~cm})$. ing may be converted to an area by using the calibration curve (Figure 2). This area value is a silhouette area but can be converted to a total surface area by multiplying by $\pi$, assuming the roots are circular in cross-section.

Two main sources of error may occur. First, roots may cross one another and this may lead to underestimates of the area. This source of error is minimized if care is taken to spread the roots out when they are laid on the plate. Second, because some roots, especially those which are actively elongating may be translucent they will not give the same reduction as equal-sized roots which are opaque. In small seedlings the roots may be dipped in a dark-coloured vegetable dye to increase their opacity. For larger seedlings the proportion of translucent roots may be so small that differences due to this factor may be ignored.

\section{Accuracy and Reproducibility}

Several tests of accuracy were made in which estimates of root surface areas of seedings, using the rhizometer, were compared with estimates ob-

\section{Table 1}

Results of measurement of root areas (a) by direct measurement and (b) by rhizometer.

Root area by Root area

\begin{tabular}{crc} 
Seedling No. & $\begin{array}{c}\text { Direct measurement by rhizometer } \\
\left(\mathrm{cm}^{2}\right)\end{array}$ & 3.9 \\
\hline 1 & 4.3 & 9.2 \\
2 & 8.0 & 9.7 \\
3 & 10.7 & 9.2 \\
4 & 12.7 & 6.8 \\
5 & 7.2 & 6.8 \\
6 & 5.9 & 7.7 \\
7 & 7.0 & 7.3 \\
8 & 8.4 & 8.2 \\
9 & 5.9 & 4.8 \\
10 & 5.9 & 9.2 \\
11 & 8.6 & 4.8 \\
12 & 5.8 & 6.8 \\
13 & 6.1 & 8.7 \\
14 & 6.5 & 16.0 \\
15 & 17.0 & 13.9 \\
16 & 9.1 & 23.2 \\
17 & 24.7 & 18.1 \\
18 & 20.2 & 14.8 \\
19 & 23.4 & 20.6 \\
20 & 19.4 & 25.3 \\
21 & 26.1 & 23.7 \\
22 & 21.4 & 27.9 \\
23 & 32.1 & 20.6 \\
24 & 20.0 & 21.2 \\
25 & 22.0 & 19.5 \\
26 & 19.6 & 25.3 \\
27 & 25.6 & 30.6 \\
28 & 27.4 & 30.6 \\
29 & 25.3 & 49.5 \\
30 & 57.4 &
\end{tabular}

Regression of rhizometer root area on direct measurement root area:

where $\mathrm{Y}=$ rhizometer measurement of root area $\left(\mathrm{cm}^{2}\right) \mathrm{R}=0.98$

and $\mathrm{X}=$ direct measurement of root area $\left(\mathrm{cm}^{2}\right)$ 
tained by direct measurement using a microscope with a calibrated eye piece to measure root diameters and root lengths. Table 1 shows data obtained for 30 jack pine (Pinus banksiana Lamb.) ranging in weights from 24 to 996 milligrams. It will be seen that a high significant linear relationship existed between estimated root surface areas

\section{Table 2}

Mean root areas (10 readings for each seedling), standard errors of means and coefficients of variation.

\begin{tabular}{cccc}
$\begin{array}{c}\text { Seedling } \\
\text { No. }\end{array}$ & $\begin{array}{c}\text { Mean Root } \\
\text { Area }\left(\mathrm{mm}^{2}\right)\end{array}$ & $\begin{array}{c}\text { Standard } \\
\text { Error of the } \\
\text { mean }\left(\mathrm{mm}^{2}\right)\end{array}$ & $\begin{array}{c}\text { coefficient } \\
\text { of Variation } \\
(\%)\end{array}$ \\
\hline 1 & 1963 & 31 & 5.0 \\
2 & 2246 & 28 & 3.9 \\
3 & 2659 & 23 & 2.8 \\
4 & 2883 & 28 & 3.1 \\
5 & 3099 & 40 & 4.1 \\
6 & 3313 & 39 & 3.7 \\
7 & 3922 & 68 & 5.5 \\
8 & 4458 & 33 & 2.4 \\
9 & 4460 & 49 & 3.3 \\
10 & 5199 & 42 & 2.5 \\
\hline
\end{tabular}

\section{Literature Cited}

ANON. 1967. Annual Report. Forest Research, Glendon Hall Laboratory. Fac. For., Univ. Tor. pp. 11.

FREAR, D. H. 1935. An improved photoelectric apparatus for measuring leaf areas. Amer. J. Bot. 24: 6: 375-376.

MITCHELL, J. W. 1936. Measurement of the area of attached and detached leaves. Science 83: 334-336. (rhizometer) and the surface areas obtained by direct measurement.

A study was made of the reproducibility of the method. Ten separate estimates of root areas, using the rhizometer were made for ten seedlings. For each seedling, no two estimates were made consecutively. The results are given in Table 2 .

\section{Applications}

This method of measuring root surface area is a rapid one. In the laboratory, the time taken to place a seedling on the plate and take a reading was slightly less than a minute. The preparation of the seedlings, i.e. the careful washing of the root systems so that no soil particles adhere is of great importance. During the latter part of 1967 over a thousand seedlings, sampled from the nurseries of the Ontario Department of Lands and Forests were measured in this way. In these nursery measurements the readings were not multiplied by $\pi$ to convert to total root area, but were designated as root surface indices.

The rhizometer has been used in the field to measure root systems of trees grown under different treatments and then subsequently outplanted. No damage to root systems from measurement has been encountered.

NEWMAN, E. I. 1966. A method of estimating the total length of root in a sample. Jour. App. Ecol. 3: 139-145.

VOIGT, G. K. 1966. Phosphorus uptake in young pitchpine (Pinus rigida Mill.) Soil Sci. Soc. Amer. Proc. 30: 3: 403-405.

WIERSUM, L. K. 1961. Utilization of soil by the plant root system. Plant \& Soil 15: 2: 189-192.

WITHROW, R. B. 1935. A photoelectric device for the rapid measurement of leaf area. J. Agric. Res. 50: 7: $637-643$. 